\title{
Offering extended use of the combined contraceptive pill: a survey of specialist family planning services
}

This article was published in the following Dove Press journal:

International Journal of Women's Health

27 September 2013

Number of times this article has been viewed

\author{
Ulrike Sauer' \\ Sue Mann ${ }^{2}$ \\ Nataliya Brima ${ }^{3}$ \\ Judith Stephenson ${ }^{2}$ \\ 'Reproductive and Sexual Health, \\ Enfield Community Service, \\ Enfield, ${ }^{2}$ Sexual and Reproductive \\ Health Research Group, Institute \\ for Women's Health, ${ }^{3}$ Research \\ Department of Infection and \\ Population Health, University College \\ London, London, UK
}

Correspondence: Ulrike Sauer Enfield Community Service, Flat 2 Rowan Court, St Michaels Site, Gater Drive, Enfield EN2 0JB, London, UK

Tel +442083752809

Fax +44208375 2888

Email ulrike.sauer@nhs.net
Background: The purpose of this study was to determine attitudes to, and provision of, extended regimens for taking the combined oral contraceptive pill (COC) by specialist contraception practitioners from three contrasting specialist contraception services in London.

Methods: An online cross-sectional survey was administered to all doctors and nurses, who counsel, provide, or prescribe the oral contraceptive pill at each clinic.

Results: A total of 105 clinicians received the questionnaire and 67 (64\%) responded. Only one of three clinics initiated and maintained guidelines for extended COC use. In that service, $60 \%$ of staff prescribing COC advised more than $50 \%$ of patients regarding alternative COC regimens. In the other two services, this was discussed with $20 \%$ and $6 \%$ of patients, respectively $(P<0.001)$. The reasons for prescribing extended use included cyclic headaches, menorrhagia, patient request, menstrual-related cramps, and endometriosis, and did not differ between the three different settings. The most common extended regimens were 63 pills or continuous use until bleeding occurs, followed by a hormone-free interval. Concerns highlighted by providers and patients were "unhealthy not to have a monthly bleed", "future fertility", and "breakthrough bleeding". Such comments highlight the need for further information for providers and patients.

Conclusion: There is growing evidence, backed by national guidance, about extended COC use, but routine provision of this information is patchy and varies ten-fold, even within specialist family planning services. Targeted training, use of service guidelines, and implementation research will be needed to extend patient choice of different $\mathrm{COC}$ regimens and change clinical practice.

Keywords: contraception, hormone-free interval, continuous combined contraception, extended pill use, counseling

\section{Introduction}

When the combined oral contraceptive pill (COC) was introduced over six decades ago, ${ }^{1,2}$ it was designed to be taken in a regimen that mimicked the normal menstrual cycle. This requires active pills to be taken for 21 days followed by 7 days without hormones, resulting in a withdrawal bleed. It has been common practice for many years to prescribe modified pill-taking regimens if unwanted symptoms such as withdrawal headaches ${ }^{3}$ or painful menstruation ${ }^{4,5}$ occur during pill-free days. These modified regimens entail taking active pills for more than 21 days and/or shortening the hormone-free interval. Such regimens are commonly termed tricyling, extended, or tailored use of the pill.

More recently, interest has focused on tailored or extended COC regimens for reasons of individual preference. ${ }^{6}$ Evidence suggests that many Western European 
women would prefer either amenorrhea or a longer interval between periods. ${ }^{6-12}$ More than $90 \%$ of health care providers also support extended pill use. ${ }^{13,14}$ In a previous study where pills were prescribed for 84 days followed by a 6-day, pillfree interval, ${ }^{12} 82 \%$ of the participating women welcomed having fewer periods and many found the regimen easier to follow.

The Clinical Effectiveness Unit of the Faculty of Sexual and Reproductive Health, which publishes guidelines for recommended standards in contraception provision, endorses the prescription of extended COC use in its most recent $\mathrm{COC}$ prescribing guideline, ${ }^{15}$ although cautions this as an offlicense use of the product. ${ }^{16}$ Whilst extended use is viewed as acceptable, there is no clear consensus over which of the many different extended regimes in use is preferable. It is also unclear what knowledge practitioners hold about extended pill regimes, to what extent these are being used in routine practice, and which various regimens are being used most frequently.

In the UK, contraception is provided by general practitioners and through specialist contraceptive services. The latter are also responsible for training doctors and nurses in contraceptive care, so play a key role in promoting innovation, service improvement, and delivering "gold standard"17 contraceptive care. We wanted to ascertain whether extended use was common or routine practice in these specialist settings, and whether there was significant variation in prescribing characteristics across different clinics. To explore these questions, we selected three specialist contraceptive services out of 15 Faculty of Sexual and Reproductive Health registered services providing training in London which are expected to be "early adopters" of innovation in practice, namely, counseling women about extended use of oral contraception. We used purposive sampling (based on known service characteristics) with the intention of revealing a range of clinical practice across specialist services, rather than aiming for a representative sample.

\section{Materials and methods}

We selected three contrasting specialist contraception services in London which had varying policies on extended COC use: the Margaret Pyke Centre, chosen immediately following the clinic's involvement in a study of extended COC use; the Enfield clinic, where a guideline on extended pill use had been introduced in association with staff training (2010); and King's College Hospital, which is an example of a newly developed fully integrated and forward-looking service, but where extended use of the COC has not been formally introduced. In April 2012, we invited all doctors and nurses in the three services who prescribe, counsel, or provide the COC to complete an adapted ${ }^{18}$ online survey (https://docs.google.com/spreadsheet/viewform?formkey=d DhTRnUwcmtvS0xXYTF5Q2EzOWZhT1E6MQ). The link was distributed through a designated staff member at each of the three locations. The questionnaire was pilot-tested in the study of Gerschultz et al. ${ }^{18}$ The average intraclass correlation was 0.69 (range 0.30-1.00), showing good reliability.

We asked about frequency of COC prescription, the reasons and conditions for which extended use would be considered, their preferred regimens, and any concerns expressed by patients or staff regarding extended use. We excluded $24 / 4$ or $26 / 2$ regimens (24 or 26 consecutive pill days followed by 4 or 2 pill-free days) as none were available at any of the three clinics at the time of the survey.

Follow-up reminders were sent on two occasions to increase the response rate. We present descriptive analyses of knowledge and provision of extended pill use, and the relationship between participant characteristics and prescribing patterns. All comparisons were made using Fisher's exact test. Odds ratios were calculated to estimate differences between clinics in providing information to patients about the extended use. All analyses were performed using Stata/ SE 12 (Statacorp, College Station, TX, USA).

\section{Results}

\section{Characteristics of sample}

A total of $67 / 105$ (64\%) doctors and nurses completed the survey. Out of these, nine of the 38 staff who did not respond were locum doctors, and six respondents could not comment on extended use in the survey because, having come from a stand-alone genito-urinary medicine service, they had not been trained to prescribe oral contraceptives.

Of those who provided COC, $84 \%$ had ever provided information to women about extended use. However, only $29 \%$ offered this information to more than half of their patients and this proportion varied ten-fold across the three clinics $(P<0.001)$. There was no difference between behavior of doctors and nurses, but frequent counseling about extended COC use was more likely to be provided by younger clinic staff and in the clinic that had developed specific local guidance. No other factors, such as age, ethnicity, or gender of health care professional were significantly different between those who prescribed extended use compared with those who did not (see Table 1). 


\section{Reasons for prescribing extended cycling regimens}

Clinicians gave a variety of reasons for prescribing extended pill regimens. These included $62 \%$ of clinicians who would prescribe if patients want to miss a bleeding because of a holiday, examination, or for cultural reasons (for patient preference, Figure 1). There was likely to be an overlap between giving patient preference as a reason for prescribing and all the other reasons given in Figure 1. One participant commented that:

"Patients seem to like the option of more than one way to take pills especially when going on holiday, travelling to a hot country, or taking exams and removing the period pain and PMT symptoms.

"Patients are reassured in the knowledge that this is not harmful."

There were no significant differences in the reasons given between the different clinics, and so data from the three clinics were combined.

\section{Types of extended regimens prescribed}

A wide range of different regimens was prescribed, of which the most common was taking three pill packets together followed by a pill-free interval, or "tricycling" (Figure 2). However, there was variation in recommended length of the pill-free interval following the 63 consecutive days of pill-taking. Twenty survey participants advised a 3 -day, pill-free interval (63/3 cycle) most commonly, 14 recommended a longer pill-free break of
7 days, and three recommended a 4-day or 5-day break, while 12 survey participants did not specify a recommended length of break. The 63/3 regimen was regarded as simple to explain to patients, with the added benefit of greater contraceptive efficacy by shortening the hormone-free interval.

Four of five respondents stated that the lack of a monthly bleed was the most common concern raised by their patients, followed by concerns about fertility (41\%) and breakthrough bleeding (38\%). Overall, 34\% of respondents felt more comfortable prescribing the standard 21/7 regimen for the COC, mostly because of lack of familiarity with other regimens. There was a desire for more evidence on prescribing recommendations, including the long-term effects of extended COC use, and for better information leaflets for users.

\section{Discussion}

Our findings show that routine use of extended COC regimens is generally low, but highly variable between settings even in the context of specialist contraceptive services. However, reasons for prescribing extended use were more uniform across the three sites and respondents expressed a desire for more knowledge and guidelines about extended use. Development of local clinic guidance does seem to have had a positive influence on extended COC prescribing in this context, although it is well known that guidelines alone often have little impact on practice. ${ }^{19}$

This was a small study of London-based clinicians that limits the generalizability of our findings. The response

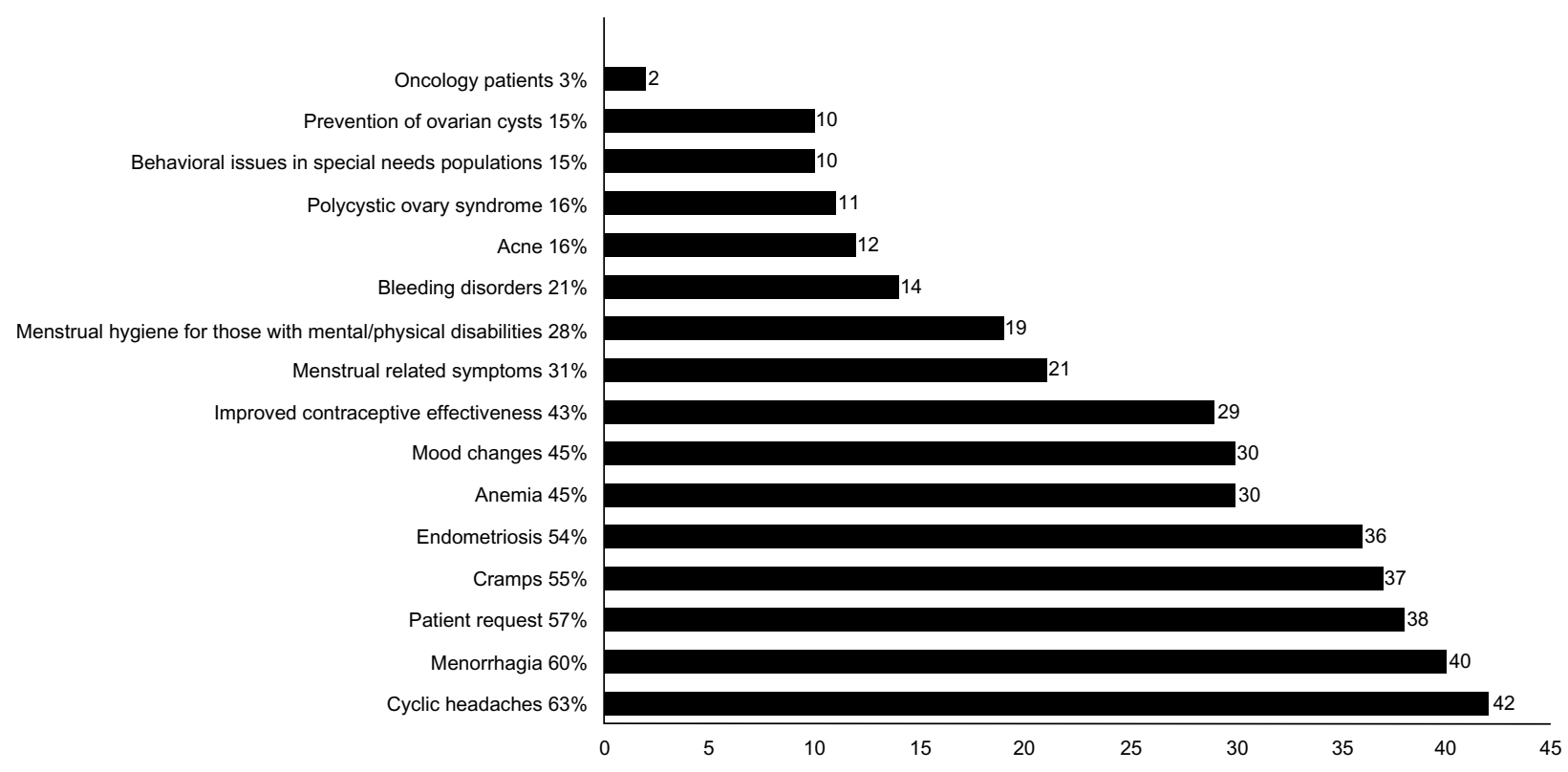

Figure I Reasons for prescribing extended cycling regimens $(n=67$ : multiple answers possible). 


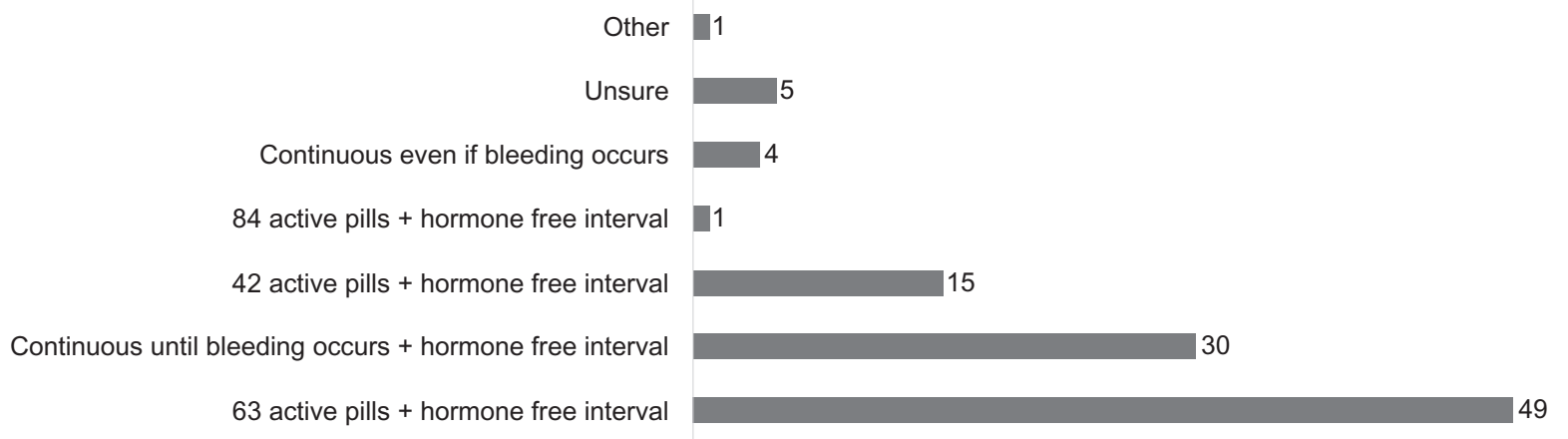

Figure 2 Type of extended regimens prescribed.

rate was lower than expected at $64 \%$ (which partly reflects non-response from locum doctors) and varied across settings, which limits the potential for cross-site comparisons especially in view of the small sample size. Furthermore, some clinical staff working in fully integrated services but previously working for a genito-urinary medicine service had not had the training to provide contraceptives.

Despite evidence from other studies that an increasing number of women would prefer to menstruate less frequently, ${ }^{6}$ most clinicians believe that the commonest concern among

Table I Characteristics of the sample $(n=67)$

\begin{tabular}{|c|c|}
\hline Characteristic & $\mathrm{n},(\%)$ \\
\hline \multicolumn{2}{|l|}{ Age, years } \\
\hline $25-39$ & $2 I(3 I)$ \\
\hline $40-49$ & $14(21)$ \\
\hline $50-59$ & $18(27)$ \\
\hline $60-74$ & $14(21)$ \\
\hline \multicolumn{2}{|l|}{ Sex } \\
\hline Male & $6(9)$ \\
\hline Female & $61(91)$ \\
\hline \multicolumn{2}{|l|}{ Setting } \\
\hline \multicolumn{2}{|c|}{ Camberwell clinic } \\
\hline Doctors & 12 \\
\hline Nurses & 9 \\
\hline \multicolumn{2}{|l|}{ Enfield Clinic } \\
\hline Doctors & 10 \\
\hline Nurses & 11 \\
\hline \multicolumn{2}{|c|}{ Margaret Pyke Centre } \\
\hline Doctors & 15 \\
\hline Nurses & 10 \\
\hline \multicolumn{2}{|l|}{ Prescribed COC } \\
\hline Ever & $61(91)$ \\
\hline Never & $6(9)$ \\
\hline \multicolumn{2}{|c|}{ Prescribed COC for extended cycle } \\
\hline Ever & $51(84)$ \\
\hline Never & $10(16)$ \\
\hline \multicolumn{2}{|c|}{ Proportion of patients offered extended COC use } \\
\hline$\leq 10 \%$ & $26(43)$ \\
\hline $11 \%-50 \%$ & $17(28)$ \\
\hline$>50 \%$ & I7 (29) \\
\hline
\end{tabular}

Abbreviation: COC, combined oral contraceptive pill. patients using extended cycles is that "it is unhealthy not to have a monthly period". In a recently completed randomized trial of extended versus standard use of an COC containing $0.03 \mathrm{mg}$ ethinylestradiol and $0.15 \mathrm{mg}$ levonorgestrel, ${ }^{20}$ we showed that tailored pill use suited some women very well and was an acceptable alternative to the standard pill. Qualitative interviews conducted during the trial $^{21}$ showed that reduced bleeding on extended use clearly suited some women very well, while others disliked the unpredictability of bleeding. To our knowledge, the only study that has analyzed clinicians' attitude to withdrawal bleeding and manipulating bleeding patterns in order to reduce pain or inconvenience associated with menses in the UK was conducted in $1977 . .^{12}$

Overall, the respondents in our survey appeared to be more enthusiastic about extended regimens than in 1977 when half of the 24 doctors and nine nurses taking part in a trial of extended pill use preferred to prescribe the standard 21/7 pill regimen, but change has clearly not been rapid.

There are now several published trials and a Cochrane review providing evidence in support of extended or tailored pill use, and this has recently been backed in the UK by national guidance from the Faculty of Sexual and Reproductive Healthcare. The Cochrane review of eight randomized trials showed similar outcomes with respect to participant satisfaction, contraceptive efficacy, and discontinuation rates for women taking a variety of extended regimens compared with traditional $21 / 7$ regimes of COC use. ${ }^{22}$ Studies also support the safety of extended use..$^{15,22,23}$ Regimens supported by the UK Faculty of Sexual and Reproductive Healthcare include tricycling (63/7), shortened pill-free interval (21/4, or 63/4) extended use (21+) with a shortened (4 days) or regular (7 days) pill-free interval, of which just the 21/7 regimen is licensed in the UK.

Anecdotally, primary care providers are more cautious about prescribing non-licensed contraceptive regimens, but specialist contraceptive services are well placed to lead 
innovation in clinical practice. To build on evidence from randomized controlled trials, we need health services or implementation research to show how guidance on extended COC use can be incorporated successfully into routine practice in busy clinics. Building on the findings of this targeted survey, we are now evaluating methods for routine implementation of extended pill guidance, including tricycling, and tailored and standard use, for all women requesting COC.

\section{Conclusion}

In conclusion, despite growing evidence backed by national guidance, routine provision of information about extended COC use is very variable even within specialist "innovative" contraceptive services. Targeted training, use of service guidelines, and implementation research will be needed to extend patient choice of different $\mathrm{COC}$ regimens and increase the pace of change in clinical practice.

\section{Acknowledgments}

We thank all members of staff at Margaret Pyke, Camberwell, and Enfield who participated in this research. The assistance provided by Emily Goodyear, Janet Barter, Punam Rubenstein, Jill Shawe, Zara Haider, Ann Baker, Nydia Mawusi, David Heron, and Andrew Bone was greatly appreciated.

\section{Disclosure}

The authors report no conflicts of interest in this work. The authors alone are responsible for the content and writing of the paper.

\section{References}

1. Dhont M. History of oral contraception. Eur J Contracept Reprod Health Care. 2010;15 Suppl 2:S12-S18.

2. Bitzer J. 50th Anniversary of the pill - What does this story teach us? Eur J Contracept Reprod Health Care. 2010;15 Suppl 2:S6-S8.

3. Boyle CA. Management of menstrual migraine. Neurology. 1999; 53 Suppl 1:S14-S18.

4. Sulak PJ, Cressman BE, Waldrop E, Holleman S, Kuehl TJ. Extending the duration of active oral contraceptive pills to manage hormone withdrawal symptoms. Obstet Gynecol. 1997;89:179-183.

5. Aubeny E. Are monthly menstrual periods optional? A European perspective. Reprod Health Matters. 2007;15:183-185.

6. Kaunitz AM. Menstruation: Choosing whether ... and when. Contraception. 2000;62:277-284.

7. Archer DF, Jensen JT, Johnson JV, Borisute H, Grubb GS, Constantine GD. Evaluation of a continuous regimen of levonorgestrel/ ethinylestradiol: phase 3 results. Contraception. 2006;74:439-445.

International Journal of Women's Health

\section{Publish your work in this journal}

The International Journal of Women's Health is an international, peerreviewed open-access journal publishing original research, reports, editorials, reviews and commentaries on all aspects of women's healthcare including gynecology, obstetrics, and breast cancer. The manuscript management system is completely online and includes
8. Harada T, Momoeda M, Taketani Y, Hoshiai H, Naoki T. Low-dose oral contraceptive pill for dysmenorrhea associated with endometriosis: a placebo-controlled, double-blind, randomized trial. Fertil Steril. 2008;90:1583-1588.

9. Birtch RL, Olatunbosun OA, Pierson RA. Ovarian follicular dynamics during conventional vs continuous oral contraceptive use. Contraception. 2006;73:235-243.

10. Legro RS, Pauli JG, Kunselman AR, et al. Effects of continuous versus cyclical oral contraception: a randomized controlled trial. J Clin Endocrinol Metab. 2008;93:420-429.

11. denTonkelaar I, Oddens BJ. Preferred frequency and characteristics of menstrual bleeding in relation to reproductive status, oral contraceptive use, and hormone replacement therapy. Contraception. 1999;59: $357-362$.

12. Loudon NB, Foxwell M, Potts DM, Guild AL, Short RV. Acceptability of an oral contraceptive that reduces the frequency of menstruation: the tri-cycle pill regimen. BMJ. 1977;2:487-490.

13. Sulak PJ, Terry Buckley T, Kuehl TJ. Attitudes and prescribing preferences of health care professionals in the United States regarding use of extended-cycle oral contraceptives. Contraception. 2006;73:41-45.

14. Wiegratz I, Galilaer K, Sänger N, Rody A, Kuhl H, Schleussner E. Prescribing preferences and personal experience of female gynaecologists in Germany and Austria regarding use of extended-cycle oral contraceptives. Eur J Contracept Reprod Health Care. 2010;15: $405-412$.

15. Faculty of Sexual and Reproductive Healthcare. Clinical Effectiveness Unit in collaboration with the Royal College of Obstetricians and Gynaecologists. FSRH Guidance. Combined hormonal contraception. CEU guidance 2011. Available from: http://www.fsrh.org/pdfs/CEUGuid anceCombinedHormonalContraception.pdf. Accessed August 26, 2013.

16. Read CM. New regimens with combined oral contraceptive pills moving away from traditional 21/7 cycles. Eur J Contracept Reprod Health Care. 2010;15 Suppl 2:S32-S41.

17. Contraception and Abortion Working Group. The time is now: Achieving world class contraceptive and abortion services. Department of Health: 2009. Independent Advisory Group on Sexual Health and HIV. Available from: http://www.apho.org.uk/resource/view. aspx?RID=74978. Accessed August 1, 2012.

18. Gerschultz KL, Sucato GS, Hennon TR, Murray PJ, Gold MA. Extended cycling of combined hormonal contraceptives in adolescents: physician views and prescribing practices. J Adolesc Health. 2007;40:151-157.

19. Francke AL, Smit MC, de Veer AJ, Mistiaen P. Factors influencing the implementation of clinical guidelines for health care professionals: a systematic meta-review. BMC Med Inform Decis Mak. 2008;8:38.

20. Stephenson J, Shawe J, Panicker S, et al. Effect of tailored versus standard use of the combined oral contraceptive on continuation rates at one year. Contraception. April 11, 2013. [Epub ahead of print.]

21. Graham CA, Panicker S, Shawe J, Stephenson J. Women's experiences with tailored use of a combined oral contraceptive: a qualitative study. Hum Reprod. 2013;28:1620-1625.

22. Edelman A, Gallo MF, Nichols MD, et al. Continuous versus cyclic use of combined oral contraceptives for contraception: systematic Cochrane review of randomized controlled trials. Hum Reprod. 2006;21: $573-578$.

23. Anderson FD, Gibbons W, Portman D. Long-term safety of an extendedcycle oral contraceptive (Seasonale): a 2-year multicenter open-label extension trial. Am J Obstet Gynecol. 2006;195:92-96.

\section{Dovepress}

a very quick and fair peer-review system, which is all easy to use. Visit http://www.dovepress.com/testimonials.php to read real quotes from published authors. 